\title{
A formação de um instituto de pesquisa como ação filantrópica Caso da Fundação JLES
}

\author{
José Luiz E. Setúbal ${ }^{1}$
}

\section{Resumo}

Mostramos como foi realizado o planejamento da estruturação de uma fundação sem fins lucrativos voltada para a saúde infantil e o objetivo de fazer ação social com ensino, educação, e projetos sociais através de um centro de pesquisa e ensino.

Palavras chave: filantropia; pesquisa clinica; saúde infantil

Setúbal, José Luiz Egydio. "A formação de um instituto de pesquisa como ação filantrópica: Caso da Fundação JLES", in Anais do 2‥ Congresso Internacional Sabará de Especialidades Pediátricas

\footnotetext{
${ }^{1}$ Mesmas informações
} 
A formação de um instituto de pesquisa como ação filantrópica - Caso da Fundação JLES

Trata-se de um trabalho descritivo sobre a criação de uma Fundação (FJES) que tem como objetivo fazer a assistência à saúde infantil através do Hospital Infantil Sabará e também é dedicada à pesquisa clínica; ensino e educação em saúde infantil, voluntariado e projetos sociais através do Instituto Pensi. Nesta atuação, pretende ser um agente de transformação social em saúde infantil.

A Fundação José Luiz Egydio Setúbal foi criada a partir da ideia de que o Hospital Infantil Sabará, com 50 anos de existência e referência em pediatria na cidade de São Paulo fosse o gerador de caixa para que a Fundação realizasse pesquisas, ensino e projetos sociais dentro da dimensão: Saúde Infantil. O Hospital foi comprado e doado para ser parte da doação na instituição da Fundação, que ocorreum no final de 2010.

Foi construído um hospital infanto-juvenil, com 110 leitos e para ser a referência em pediatria na medicina suplementar na cidade de São Paulo. O resultado financeiro deste hospital seria usado inicialmente para pagar as dívidas de R \$100 milhões e depois para alimentar um Fundo Patrimonial que será responsável para garantir a perenidade da Fundação e de fomentar as pesquisas, a educação e os projetos sociais, sempre na Saúde Infantil.

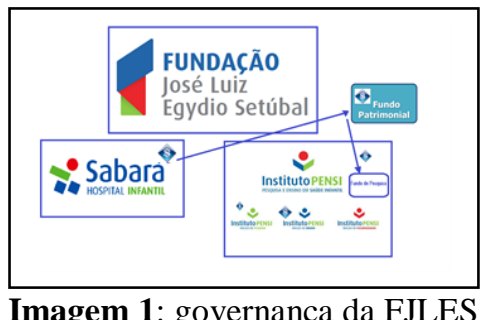

Núcleos de Pesquisa do Instituto Pensi

Nutrição e Metabolismo: coordenação Professor Dr. Mauro Fisberg Respiratórias e alérgicas: Assessoria Professor Dr. Dirceu Solé Doenças Imunológicas: Parceria com Professor Dr. Antônio Carlos Condino Infecciosas e imunizações: coordenação Professor Dr. Marco Aurélio Sáfadi Primeira Infância - Coordenação do Professor Dr. Lino de Macedo Neuropsicológicas - sendo estruturado com Dr. Edson Amaro e Dra. Glaucia Faria 
Fluxo dos protocolos patrocinados - FJLES

(laboratórios farmacêuticos)

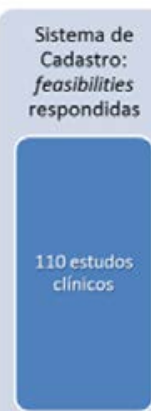

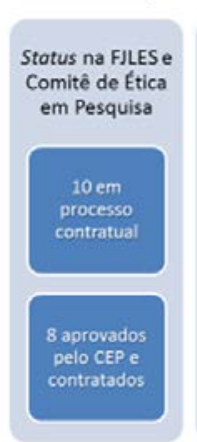

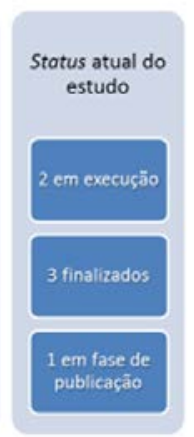

Fluxo dos protocolos institucionais - FJLES

Corpo clínico (HIS) e pesquisadores parceiros (PENSI)

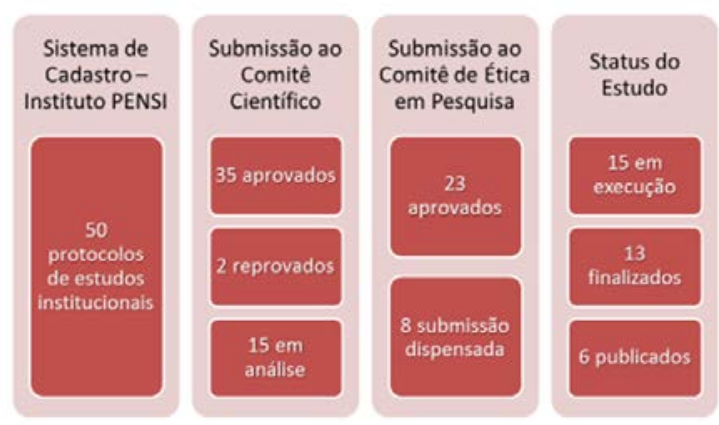

Áreas dos feasibilities para estudos clínicos patrocinados em 2014

$$
(n=18)
$$
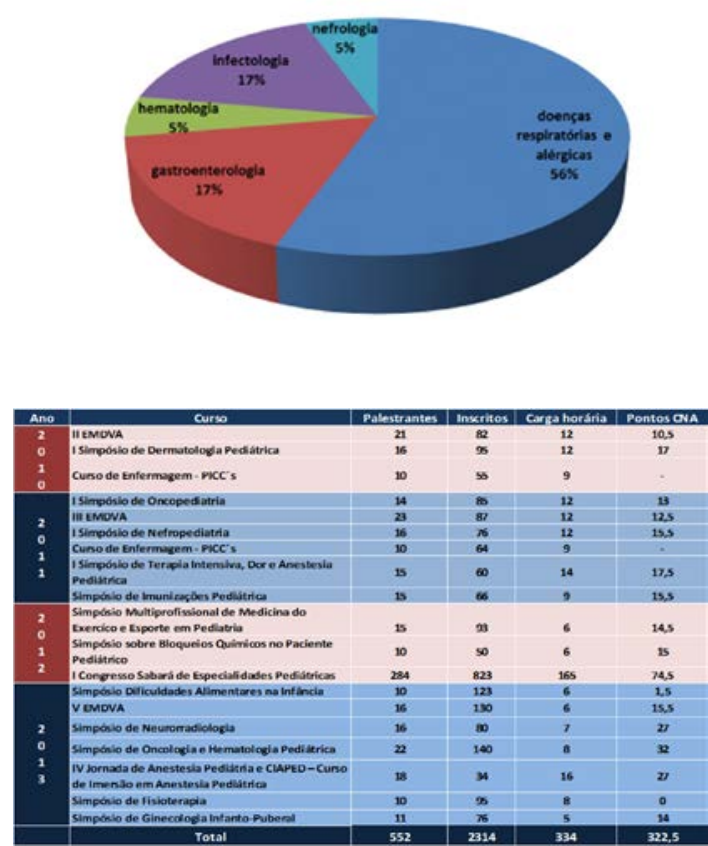

\begin{tabular}{|c|c|c|c|c|c|}
\hline Ano & Evento & $\begin{array}{c}\text { Palestrante } \\
\text { s }\end{array}$ & Público & $\begin{array}{c}\text { Carga } \\
\text { horária(hs) }\end{array}$ & $\begin{array}{l}\text { Pontos - } \\
\text { CNA }\end{array}$ \\
\hline \multirow{2}{*}{$\begin{array}{l}2 \\
0 \\
1 \\
0\end{array}$} & $\begin{array}{l}\text { Excelência em Pediatria - } \\
\text { EducaSus / FCMScSP } \\
\text { (videoconferencia) }\end{array}$ & 12 & 397 & 18 & 12 \\
\hline & $\begin{array}{l}\text { Condutas Pediátricas } \\
\text { (CBBW-streaming) }\end{array}$ & 60 & 573 & 84 & 10 \\
\hline \multirow{2}{*}{$\begin{array}{l}2 \\
0 \\
1 \\
1\end{array}$} & $\begin{array}{l}\text { Excelência em Pediatria - } \\
\text { EducaSus / FCMScSP } \\
\text { (videoconferencia) }\end{array}$ & 32 & 798 & 48 & 24 \\
\hline & $\begin{array}{l}\text { Condutas Pediátricas } \\
\text { (CBBW- streaming) }\end{array}$ & 40 & 266 & 56 & 10 \\
\hline \multirow[t]{2}{*}{$\begin{array}{l}2 \\
0 \\
1 \\
2\end{array}$} & $\begin{array}{l}\text { Excelência em Pediatria - } \\
\text { Educasus / FCMSCSP } \\
\text { (videoconferencia) }\end{array}$ & 16 & 292 & 24 & 12 \\
\hline & Total & 160 & 2326 & 230 & 68 \\
\hline
\end{tabular}

Atuação do Voluntariado:

Capacitação de mais de 1.100 pessoas em 5 capacitações por ano. Hoje contamos com 140 voluntários com 1500h/mês de trabalho voluntário.

Parcerias com:

- Associação Viva e deixe Viver (prof. Valdir Cimino)

- Associação Arte e Despertar

Projetos sociais:

- Rede Nacional da Primeira Infância

- Observatório da Primeira Infância

- FMUSP

- Projeto Bandeiras Científicas com alunos da USP 
- Fundação Maria Cecília Souto Vidigal

- Projeto em Coroados em São Paulo

- Núcleo Ciência Pela Infância

- Instituto Saúde e Sustentabilidade

- Virada da Saúde de São Paulo

- AMEO (Ass. Medula óssea)

\section{English Title: Creating a research center as a philanthropic action}

Abstract: We show how we do the planning of structuring a non-profit foundation dedicated to children's health with the goal of making assistance, research and education with social action.

Our project of education, and social projects will be doing through a research and education Center (Instituto Pensi) and the assistance on child healthy in Sabará Children Hospital.

Keywords: philantropy. Research center. Child healthy

\section{Referencias}

Conceito Empreendedor Social. Ashoka Brasil. Disponível em: http://brasil.ashoka.org/conceito-0

WHO definition of Health. World Health Organization. Disponível em: http://www.who.int/about/definition/en/print.html 